\title{
The Health of Soil Ecosystem as Self-maintenance and Sustainable Bioproductivity Review article
}

\author{
A. M. SEMENOV ${ }^{1 *}$, M. S. SOKOLOV ${ }^{2}$, A. P. GLINUSHKIN ${ }^{2}$ and V. I. GLAZKO ${ }^{3}$ \\ ${ }^{1}$ Department of Microbiology, Biological Faculty, Lomonosov Moscow State University 119234. \\ Lenin's Hills, 1, 12 Moscow, Russia \\ ${ }^{2}$ Russian Research Institute of Phytopathology, Fano. 143050 Moscow, Odintsov Region., \\ w.s. Bolshye Vyazemy, Institutskaya str., b. 5, Russia \\ ${ }^{3}$ Russian State Agrarian University - MAA named after K. A. Timiryazev, 127550 Moscow, \\ Timiryazevskaya Str., 49, Russia
}

(Received: 29 August 2016; accepted: 15 September 2016)

\begin{abstract}
In the review traditional characteristics of the soil quality are discussed. Soil health (SH) along with its soil quality and fertility, is considered as the most important, functional characteristic of any soil ecosystem (SE). The consistent patterns and results of the study of structure and functions of the microbial community (MC) of the soil ecosystem were generalized to substantiate the quantitative parameters of soil health. The author's developments for definitions of soil and soil health are given. The prospects of using the parameters of SH for diagnostics at recovery and biological rehabilitation of technogenically disturbed soils are proposed.
\end{abstract}

Keywords: soil, soil ecosystem, soil health, microbial community, parameters of soil health, plant health, diagnostics, rehabilitation of soil.

The soil is endowed with many properties, features and functions that were studied in detail. Among them two are recognized as general characteristics: soil quality and soil fertility. soil fertility (actual and potential) is most often regarded as its consumer characteristics. The traditional definition of soil fertility is the ability of the soil to provide the plants with the mineral elements, water, air, and in general providing their normal ability to live in the favorable physical and chemical environment. In recent years, attempts have been made to expand the concept of "soil fertility" and supply it with new content (Kirjushin, 2011).

Soil quality characteristic of natural and agro-ecosystems, compared with fertility, has considerably broader meaning, and devoid of a specific dimension. This concept encloses scientifically - informative and consumer aspects. It includes a number of properties of the soil, which to a greater or lesser degree are changed in the process of technological impacts. Colleagues from the Soil Science Society of America (SSSA) determine the quality of the soil as "the ability of the soil to function within the boundaries of the

* Corresponding author; e-mail: amsemenov@list.ru 
ecosystem to maintain its biological productivity and quality, ensuring the health of plants and animals" (Carpenter et al., 2001; Karlen et al., 1997; Sokolov et al., 2010). Although such a definition of soil quality puts its physical and chemical characteristics on top, but it also includes its biological properties (Semenov et al., 2011; Van Bruggen and Semenov, 2000). Earlier in the United States and Canada not only methods and parameters have been developed, but even portable devices and sets of tools for the determination of the quality of the soil had been produced (Environmental Box Kit Soil quality) (Liebig et al., 1996). Registered parameters include: the conductivity of soil, its $\mathrm{pH}$, resistance during of plowing, density, conditioned index (content of native organic matter), organic carbon and carbon microbial biomass, humidity, moisture capacity, filtering capability, soil pore space, temperature, soil respiration, nitrates content and more etc. (Semenov et al., 2011; Karlen et al., 2008). Up to 100 indicators of soil quality have been proposed (Van Bruggen and Semenov, 2000; Karlen et al., 2008; Arias et al., 2005). A multivariate analysis was proposed to streamline this diversity of indicators (Liebig et al., 1996; Janvier et al., 2007). Several indexes of soil quality, evaluating methods of soil cultivation (a type of tillage, crop rotation, type and method of fertilizer, etc.) and correlated with the amount and quality of the crop were tested. The pinnacle of these efforts was an attempt to derive a quantitative formula of assessment of soil quality (Karlen et al., 2008; Janvier et al., 2007).

The advantage of this approach is the assessment by means of these indexes of the physical, chemical and partially biological characteristics of the soil, intention to substantiate the complex approach to the assessment of soil quality. The disadvantages are the empiricism of these indicators, the subjectivity of experts in justifying the choice of its number and importance. Thus, today this problem is far from being solved despite some progress in the search of soil quality indicators. Moreover, the proposed characteristics of soil quality could not cover and satisfactorily explain all the new facts established by related sciences, especially biology. There is a need not only to integrate these new facts, but to form a new understanding, which has been manifested in the justification of a new biological category of soil - its health.

The authors attempted to examine conceptually the formation and development of the category of "soil health" (SH), initially considering the soil as a natural ecosystem, and soil of agro-ecosystems - as a derivative of the natural soil. It was important to show the influence of the evolution of knowledge of ecosystems on the formation of the concept of SH, suggest methods for the quantitative determination of parameters of SH, delineate the scope of application of the strategy of SH and finally suggest a method of quantitative determination of functional parameters and to identify the factual criteria for the $\mathrm{SH}$ for the rehabilitation of technologically disturbed soils.

\section{On the concept of soil health}

The soil is considered as a product of long-term mutual assimilation and dissimilation activities of microorganisms and plants in the dominant mineral-organic substances. The present natural soil is organic - mineral product created and maintained in accordance with the local climatic regime and continuous, mostly microbe-plant interaction in 
initially quantitatively dominant inorganic substances. Along with the latter, the soil contains geobionts, their residues, metabolites and compounds of biophil elements. Basic biological, physical and chemical processes such as biogeochemical cycles of elements and cycles of microorganisms take place in the soil. The soil has a significant buffering effect against a variety of stressors, provides geobionts and plants with nutrients, acting as a source and pool of biodiversity (Semenov, 2015; Semenov and Sokolov, 2016).

Concept of SH has arisen in the late eighties - the beginning of 90th of the XX-th century (Doran et al., 1996; Doran and Zeiss, 2000; Semenov et al., 2011). The appearance of this characteristic was induced by social and scientific reasons. In economically progressive countries the understanding and development of the concept of SH originated due to the high requirements for food and feed quality, as well as due to concern for the fate of the soil state. This has led to a number of the definitions which today dominate in conceptions of SH (Karlen et al., 1997; Sokolov et al., 2010; Karlen et al., 2008; Doran et al., 1996; Doran and Zeiss, 2000; Anderson, 2003). There is also an opinion on the need to consider physical and chemical indices of soil quality as the components of its health (Semenov et al., 2011; Van Bruggen and Semenov, 2000; Semenov, 2015). An example of this approach is given in the work (Sokolov et al., 2010): "Health of the soil is a function of its environmental sustainability, including: a) optimally balanced and adapted (to the ecological resources) biodiversity of pedocenosis; b) self-purification of soil from pollutants through adsorption and (or) of biotransformation; c) the suppression of harmful biota (phytopathogenic and sanitary indicative) by dominated aboriginal soil microorganisms". Thus, such definition of SH as category took the mixed status in the characteristics of the soil.

In order to correctly understand the essence of concept of health of soil, it is necessary to distinguish the category to which the soil belongs, is it a natural soil, or agro-ecosystem soil, because the "strategies" of their development differ considerably. The first category has advance to stability, climax and equilibrium condition of its efficiency and productivity. On the contrary from agroecosystem high efficiency is required constantly, thus while estimating the health of soil it is necessary to consider not only biological, but also social and economic aspects. Taking the last into account the healthy soil of agroecosystems is a fertile soil, not polluted and not infected, that is standard pure soil.

Among numerous characteristics and requirements to healthy soil invariably there are such characteristics of quality and health, as resilience, resistance, stability, redundancy and boundaries of ecosystem (Janvier et al., 2007; Griffith et al., 2001; Orwin and Wardle 2004; Kuan et al., 2007). Resilience and resistance is an ability of soil components (biotic and abiotic) to resist and recover quickly after disturbing influences that has something in common with concept of stability of a soil ecosystem. Stability is also an ability of soil ingredients to resist the violating effects that resonates with the notion of the resistance of the soil ecosystem. Of course mentioning of these characteristics emphasizes the need to use multi-faceted approach for analysis of soils on different ecosystem levels. However, resilience and resistance of soil can be estimated by its buffer value, particle size and granulometric structure, water-holding capacity, but also by the ability of its microbial communities to return after perturbations to the initial conditions. It is possible to discuss with the similar approach also the importance of the phenomena of the "redundancy" in soil, the great significance of definition of the soil ecosystem boundaries, 
etc. The above characteristics have a common drawback. This is the lack of accelerated methods for determining and specific dimensions and comparisons. This also applies to such requirements to the soil ecosystem, as the need for "high biodiversity" (Garbeva et al., 2004; Van Bruggen and Semenov., 2015; Mader et al., 2002; Buyer and Kaufman, 1996; Van Bruggen and Semenov, 1999), the "closed" cycle of biophilic elements and suppressive abilities in the relation of plants pathogens (and even any pathogens) for ensuring high and sustainable harvest!

\section{Soil health and effect of some agronomic techniques}

It has experimentally been shown that some, listed above, soil health characteristics coincide, maintain and/or even amplify at certain system of cultivation of soils. In agroecosystems $\mathrm{SH}$ is often associated with the system of organic (bioecological) agriculture (Van Bruggen and Semenov, 2015; Finckh et al., 2015; Mader et al., 2002). It supposes the use of only organic fertilizers, biological or physical of protection against harmful organisms, a complete rejection of pesticides and using of genetically modified organisms. Indeed, the system of organic farming provides better physical and chemical characteristics of soil (Van Bruggen and Semenov, 2015; Finckh et al., 2015; Mader et al., 2002; Van Bruggen and Semenov, 1999). This significantly increases biodiversity of micro- and macro biota. Experimentally it was confirmed that increased microbial diversity of healthy soil hinders mass development of pathogenic microorganisms, possibly it's due to the changes in the circulation of nutrients in such soil. However resistance and resilience of a soil ecosystem, for example, to mass development of phytopathogens can be quantitatively estimated only by method of comparison (Carpenter et al., 2001; Griffith et al., 2001; Orwin and Wardle 2004; Semenov and Sokolov, 2016) that is not acceptable for practical use. Thus, although the problem is designated at this time period, it has no practical solution. Marking appeal and validity of some empirically revealed indicators of quality and $\mathrm{SH}$ in organic agriculture it is necessary to recognize that they all are being based on expert estimations, have only correlative, instead of fundamentally biological substantiation (Epelde et al., 2014).

\section{The concept of SH as a reflection and influence of new laws and facts of the general and microbial ecology}

The origination and formation of the phenomenon of SH has occurred under the influence of a number of the new facts revealed in the functioning of the ecosphere in recent years. Among these are the laws of growth and development of biological populations: (1) the exponential growth of populations, (2) self-limiting of growth, i.e. limiting and/or inhibiting the growth of populations, and (3) wave-like or oscillating development of populations in time and space (Turchin, 2002; Semenov, 1991; Semenov, 2005, 2011). More specific laws called concepts has also been established, such as: 
"actual and potential activity of soil microbial community"; "concepts of microbial pool and redundancy of the pool in soil and other ecosystems compared to the amount of nutrient available"; "concepts of functional parallelism among microorganisms, or functional duplication"; "microzonality of soil as a habitat for microorganisms"; "concepts of "evolutionary development of microorganisms in the community and through the community"; "dependence of the significance of the process in an ecosystem from number and activity of microorganisms which carry it out», etc., (Turchin, 2002; Semenov, 1991; Semenov, 2005, 2011). Some of them are listed in the monograph of D. G. Zvyagintsev (Zvyagintsev, 1987). However, the central concept of microbial ecology is certainly the concept of the structure of microbial community, that possessed flexibility, predictability and universality (Semenov, 1991; Semenov, 2005; Semenov and Van Bruggen, 2011.).

Recently we had been put forward the new concept in microbial ecology about «disturbing actions and wave-like development of microbial populations and communities». This concept has allowed not only to generalize our numerous results, but also to create scientific basis for understanding and a substantiation of phenomenon SH (Semenov, 2005; Semenov, 2011; Van Bruggen et al., 2006). Taking into account the above-stated the detailed scientific definition of health of soil was proposed. Health of soil is a biological category, reflecting the state of the dynamics of the activity of the biotic component in the organic-mineral complex of soil; the healthy soil is characterized by adequate, corresponding to natural and climatic zone dynamics of activity of biotic processes (synthesis and hydrolysis), their stability to disturbing actions (biotic and abiotic), "completeness" of cycles of biophilic elements and cycles of microorganisms, irrespective of consumers inquiries; the healthy soil of agroecosystems is characterized also by conformity of its quality to standard indicators and acceptable fertility. From above definition, it follows that the idea of soil health should not be mixed with consumer requirements to quality of soil, and that quantitative features and methods are necessary for an estimation of health of soil (Semenov and Van Bruggen, 2011; Semenov 2015; Semenov and Bubnov 2013; Drury et al., 1991; Fauci and Dick 1994; Polyanskaya and Zvyagintsev, 2005). However, until recently among indicators of soil health (by analogy to indicators of soil quality) dominates the set of characteristics of "inhabitants" of soil and their processes and/or metabolism products, produced by them. Among them: indicators of soil respiration, the microbes biomass (defined by indirect methods), number of bacteria and mycelium length of fungi, a microbial diversity, the variety of bacteria, fungi, micro-alga (for example, in the form of indexes of Shannon, Berger-Parker, etc.), and also number of the protozoa, nematodes and other micro- and meso- faunae. Justification of their usage as indicators of health (and quality) of soil is provided by the data of response of a biomass of microorganisms, a relation of fungi and bacteria etc., to the techniques of soil processing, the application of mineral fertilizers, the plants residues, a crop rotation etc. (Drury et al., 1991; Fauci and Dick 1994; Polyanskaya and Zvyagintsev, 2005). Hence, there was an understanding that SH is, undoubtedly, biological category, however quantity indicators and the parameters for estimating of $\mathrm{SH}$ are necessary. 


\section{Parameters for quantitative assessment of health of soil; heterotrophic parameter of soil health}

Finding wave-like dynamics in the number of bacteria along the roots of wheat gave the impulse for authors to a comprehensive study of this phenomenon: in the rhizosphere and non-rhizosphere soil, for saprotrophic, phyto- and enteropathogenic microorganisms, the dynamics of natural populations (in microcosms and pure cultures), involving the microbiological, molecular-biological methods and mathematical modeling (Semenov et al., 1999; Semenov and Bubnov 2013; Zelenev et al., 2006). For obtaining and studying the wave-like dynamics of growth of the microbial population it needs to have a representative number of daily measurement data, for example, as CFU or soil respiration (Semenov et al., 2013). Harmonical (Fourier) analysis of this data allows to reveal harmonical components with high reliability, separating them from random variations, and to define parameters of authentic oscillations (harmonics). Using this method has convinced the authors of scientific certainty and knowledge of the biological essence of wave-like dynamics of microbial populations (Semenov et al., 1999; Semenov, 2001). The authors have been convinced of the universality and the generality of this phenomenon and formulated the environmental concept of "disturbing actions and wave-like dynamics development of microbial populations and microbial communities" (Semenov, 2001). Key points of the declared concept are: (I) microbial populations (MP) and microbial communities (MC) exist and develop in a wave-like way (cyclical) in time and space; (II) the reason for the wave-like development of MP and MC is an interaction between the consumer and the substrate with alternating phases of growth and dying off (wavelike mechanism); (III) the driving forces of wave-like development - constantly arising in the system the disturbing actions of inward and outward nature, leading to fluctuation in a number, activity and a biodiversity of inhabitants of a soil ecosystem; strong external factors "organize" the constantly arising "spontaneous" fluctuations of microbial populations and communities, and "arrange" the "impulses" of nutrients which are formed at the time of actions; (IV) disturbing actions are any stressors that lead to "introduction" of nutrients to local microecosystem or removal of limiting and/or inhibiting factors, including drying, moistening, freeze-thaw, mechanical stress, addition of substrates, etc.; (V) circulation of microorganisms in the nature in itself, in a form of "a microbial cycle" and furthermore simultaneously with organic substrate, "the microbial cycle" serve as universal and constant distorting factor for natural MP and MC (Semenov et al, 2011; Semenov and Sokolov, 2016; Semenov et al., 2010).

Comprehension of phenomena of wave-like dynamics of microbial populations led to the development of a method for determining parameter of soil health on the dynamics of release of $\mathrm{CO} 2$ from soil or other substrates (substances) (http://bankpatentov.ru/ node/62779) (Semenov et al, 2011a). It is well known that the rate of CO2 emissions from soil is an indicator of intensity of biological processes, summarizing the activity of bacteria, fungi, animal and even plant components. Adding the substrate (into soil) is a powerful disturbing factor and the rate of substrate-induced respiration (SIR) has traditionally been widely used not only in soil microbiology. 
Key positions for the method of determining of soil health parameter, as well as the subsequent, are obligatory several principles: 1) to use the comparisons of soil being studied with the soil chosen as "healthy" (conditionally "referenced" or "conventionally" healthy), of the same genesis and a landscape (it is principle of comparison); 2) to use for determination of SH parameter only fresh, fresh the selected samples the soils (it is principle of freshness), 3 ) to use the same and adequate for the soil disturbing factor or stressor (principle of initiation), 4) only in dynamics, at least daily, to determinate (SIR) samples of soils is necessary (dynamism principle). In the proposed method glucose is used as disturbing factor and is applied to conventionally-healthy (control) (Lcon) and examined samples (Le) of soil (Semenov et al., 2013; Semenov et al, 2011a). Daily for 5 days the dynamic $\mathrm{CO} 2$ rate $(\mathrm{V})$ from the soils under controlled conditions of temperature and humidity has been appraised. A well-selected disturbance led to a wave-like V response. Dynamics plots of the dependency of $\mathrm{V}(\mathrm{t})$ have been built, using the experimental the data. One of the first, most high peak (i.e. with the highest amplitude) of the graphically represented dynamics was selected for the both examined and control samples. The peak's width was measured at a half-height of the peak (L) for the examined soil (Le) and the control soil (Lcon), and the SH parameter was calculated according to the formula: $\mathrm{SH}=\mid($ Lcon - Le $) /$ Lconl. The using of absolute value for expressing of the results instead only the results of subtraction enables correct carryout comparison the results and the measuring units ignore. The closer a calculated SH parameter is to a zero, the more healthy the examined soil is considered. A zero result means that the examined soil is absolutely healthy in comparison to conventionally-healthy (control) soil (Semenov et al., 2011; Semenov et al., 2013; Semenov et al, 2011a).

\section{Determination of parameter of health of the soil enriched by biophylics elements, as an indicator of "closeness" of the cycles biophylics elements}

It is necessary to remind that parameter of soil health due to the biological meaning can be called as heterotrophic parameter of soil health (HPSH), emphasizing that a reaction of heterotrophic microbial community (in the form of SIR) on the enrichment of the soil with organic substrates, is the essence of the parameter. However, the importance of the information about the "closed" state of cycles of biophilic elements, primarily nitrogen $(\mathrm{N})$, phosphorus $(\mathrm{P})$ and etc., in the soil ecosystem, is emphasized in the majority of publications about soil quality and soil health (Semenov et al., 2011; Van Bruggen and Semenov, 2000; Van Bruggen et al., 2006; Finckh et al., 2015). It means for health of the soil ecosystem to possess ability to provide itself by biophilic elements is very important.

We have studied the dynamics of biological processes, primarily $\mathrm{N}$ compounds in the form of its entry into the soil ecosystem: nitrogen fixation and ammonification and removal of $\mathrm{N}$ from the soil ecosystem as nitrification and denitrification. First of all we had realized that using one-time and static assessment of concentrations of $\mathrm{N}, \mathrm{P}$ and other biophiles elements that accumulated in the soil instead of dynamic approach is not correct for understanding that "closed or not" the cycles of biophilic elements in this soil. 
Second, our dynamic experiments (in the form of daily long-term measurements) have shown that the processes of nitrogen fixation and ammonification in the soil ecosystem cannot be recommended as routine parameters for estimation of "closeness" or "openness" of processes of flowing of nitrogen into the soil (Emer et al., 2014; Semenov and Sokolov, 2016). For a long time all it is known that biological processes of removal of $\mathrm{N}$ from soil in the form of nitrification and denitrification also have fundamental limitations and cannot be recommended as indicators for routine estimations of the daily loss of $\mathrm{N}$ from soil (Semenov and Sokolov, 2016). Thus, a traditional and even dynamic approach to determination of the status of cycles of biophilic elements in soil is not acceptable and different solutions are required.

It is proposed to estimate a state of biophilic elements in these soil ecosystems by the method of substrate induced of respiration but after simultaneous and joint enrichment of the soil microbial community by carbon, nitrogen, and if necessary with phosphorus. It means that an approach is used similar to the heterotrophic parameter of soil health quantification and the enrichment of these soils by biophilic elements and carbon is considered as a disturbing action. Hereby novel parameter for estimating of the soil ecosystem reaction on nitrogen delivering is similar to the heterotrophic parameter of SH determination is proposed, when is used the rates of comparison $\mathrm{CO} 2$ emission from two soil samples under controlled conditions by enrichment of the soil by organic carbon and inorganic nitrogen, for example (NH4NO3). These suggestions are based on well-known, widely accepted and logically not contradictory to each other scientific positions, with experimental support (Demoling et al., 2007).

Given that while using proposed method of "the estimation of nitrogen delivering in soil ecosystem" when the "peak-like graph" is also formed (peaks of soil induced respiration) just as well as at determining heterotrophic parameter of soil health, it is proposed to use the same approach to calculate this novel parameter.

It is proposed to carry out the calculation of the parameter of $\mathrm{SH}$ enriched with biophilic elements on the graphs(s) of the $\mathrm{V}$ on $\mathrm{T}$, using the same methodological procedures as a parameter in the calculation of heterotrophic parameter of $\mathrm{SH}$ (Semenov and Bubnov, 2013). Thus, the state of the soil cycles of biophilic elements ("closeness" - openness) is proposed to assess by change in the index of SIR under the influence of the inductors of this process. It is accepted if the value is SIRcon $=$ SIRe the state of these cycles is correct. The solution of the questions caused by the arising of deviations from equality of values in above equation, the significance of such deviations etc., are solved by increase and accumulation of the experimental data achieved by this method for different soils.

Experimental determination of the induced parameter - the reaction of the microbial community of soil on the biophilic elements - has demonstrated acceptable validity, sensitivity and reproducibility of the proposed method (Semenov and Sokolov 2016).

\section{On the relationship of soil health and plant health}

Discussion of a theme of soil health claim at least shortly to mention the relation of soil health with growing on the soil the plants and of course the health of plants. At 
discussion what is the soil quality and soil health Doran J.W. and representatives from the American Society of soil scientists (SSSA) in the list of the characteristics of these categories, the health of plant (PH) was noted of course as one of the main characteristics (Doran et al., 1996).

The category of plant health, from a consumer's standpoint, can be expressed as the properties of the plants capable to reach statistically average quantity and quality of its products, growing in accordance with local climatic regime during the growing season, on the unit of local area of the soil ecosystems (SE). Accordingly, a healthy plant is not a sick plant, a plant that can reach statistically average quantity and quality of their productivity and accomplish their life-cycle in accordance with local climatic regime, the growing season and the soil ecosystem. If the plant does not reach these characteristics, this plant or sick, or to suppress by environments.

Undoubtedly that the health, growing on the soil of plants substantially depends or even is completely defined by the health of soil ecosystem that is shown by uncountable works (Finckh et al., 2015). Of course, we can assume that "to some extent, in unhealthy soil" can get an acceptable quantity and quality (healthy!) of the crops. This assumption reinforces the evidence of integrality the health of soil and plants, dependence and connection of health of plants from soil ecosystems and of course the types of agriculture, i.e. conventions or organic agriculture. Very importantly to note that links of soil health and health of plants is especially evident at the transition from convention to organic system, as well as at carrying out the soil ecosystem oligotrophication (Semenov et al., 2011; Van Bruggen and Semenov, 2015).

However to remind, the category of health of plants is population-based property, property, subordinated to the laws of development of populations. Soil health is also based on the populations, microbial populations. It brings together biology and $\mathrm{PH} \mathrm{SH}$. However such generality on it comes to an end. The essential biological characteristics of microorganisms and plant populations are very different. Plant health, as well as plant disease is depends from: the current state of the physiology of the individual plant, which depends on the ambient conditions. Plant health depends on soil ecosystem health and activity of the pathogens. Pathogens of plants, if especially are the microorganisms possess in the "general" cycle (circulation of microorganisms) the micro-cycles. The microcycles of pathogens can be as above-ground and below-ground the life cycles and the plants can have phases in of plant development (Agrios, 1997). If diagnostics of the plants diseases develops successfully but the methods of therapy of plants, control of plant pathogens, especially unification of methods of therapy of plants, demands the further tough works. For the solution of these century problems new, nonconventional approaches are necessary.

\section{The perspectives of adopting of the parameters of SH for diagnosis and rehabilitation of unhealthy soil}

It is reasonable to discuss the possibility of the application of the parameters of soil health for diagnosis and the therapy of technologically disturbed soils. In social sphere, in medicine, along with "health" concept, health maintenance, prophylaxis and also treat- 
ment (therapy) are used. It is evident that before of "treatment" should be done of diagnosis. It is necessary to know that there are difficultly diagnoses, hard to cure and even "incurable" diseases exist.

We know that as a result of determination of heterotrophic soil health parameter a numerical indicator (at comparison of two soils) is received which can be used for the diagnosis and treatment of examined soils. Such indicator numerically can be equal to, lower or above zero. Legitimate questions about the extent of "below" or "above", how significant these differences are, as well as questions about "drugs" and their concentrations", the duration of treatment can only be answered through the use of "databank" of the different ecotypes of $\mathrm{SH}$.

In order to have the diagnosis about a condition of biophilic elements transformation in the soil ecosystem (the closed/opened cycle) it is necessary to determine the SH parameter and assess the reaction of its on biophilic elements enrichment. Such determinations will help to make an objective diagnosis and answer the question, if soil is impoverished or "overfed" with biophilic macro- and/or microelements?

Health of soil ecosystems can suffer also as a result of uncontrolled development of any soil plant pathogens and/or pathogens of warm-blooded animals. This problem, obviously, can be clarified by analyzing the parameters of $\mathrm{SH}$, and classifying these soils according to the degree of suppressive or conductive. Undoubtedly, for this purpose it is necessary to be the observant and competent expert (owner!), deeply knowing background of reference and investigated soil. The "treatment" of such diseases is possible with: (a) restoration of balance of Corg, biophylics elements or that and another; (b) observance of balance of others (mico) -elements; (c) agrotechnics, keeping in mind that the soil can be heavily or is incurably sick.

\section{Conclusion}

For a very short period of time in comparison with the time, dedicated to researches of fertility and quality of soil, in a problem of soil health a considerable progress is already reached. Progress includes: judgement and belief in necessity of the new biological characteristic of a soil ecosystem - soil health, development of methods of SH determination, methods of diagnosing of the soil ecosystem health, methods of rehabilitation ("treatment") of soil ecosystem. It has occurred due to considerable successes in biology and ecology of microorganisms. Existence of laws of population biology is realized. There is a progress in knowledge of microbial community structure. Progress in understanding and comprehension of the fact that contemporary soil is a product of functioning of an ecosystem, a product which has arisen and exists due to joint activity of microorganisms and plants in quantitatively dominating inorganic substance.

Fast development of representations and methodical decisions in determination of health soil parameters, diagnostics of soil health and the soil ecosystem improvement ("therapy"), of course, put forward the following problem - the creation of complex, accessible, fast and effective methods, which harmonize a combination of biological, physicochemical and production examinations of a soil ecosystem. 
However unsolved problems are remaining. Developments of accessible, fast and effective methods of pathogens biocontrol are necessary, first of all, of the plants, as most difficult and complex problem, and of course of the animals. Complexity of phythopathogens biocontrol problem is that phytopathogenic microorganisms have in the general microbe cycle, i.e., a cycle of microorganism's circulation in ecosystems, occurrence of microcycles. Micro cycles show up in the existence over- and inside of soil cycles of these microorganisms, and also presence of phases in growth of plants make this problem very difficult to solve, impede the development and unification of methods. For their decision new, nonconventional approaches are necessary. One of approaches to solving this problem - understanding and determination of priority, domination of particular cycle in the set of (micro)cycles on which it is necessary to concentrate the basic impact!

\section{Acknowledgements}

The authors are very thankful to Profs. Van Bruggen, A.H.C. and Finckh M.R. for the publishing of the unique Book "Plant Diseases and Their Management in Organic Agriculture" which will serve scientists and experts always.

\section{Literature}

Agrios, G. N. (1997): Plant Pathology. Fourth ed. Academic Press, San Diego, USA, 635 p.

Anderson, T. H. (2003): Microbial eco-physiological indicators to assess soil quality. Agric. Ecosyst. Environ. 98, 285-293.

Arias, M. E., Gonzalez-Perez, J. A., Gonzalez-Vila, F. J. and Ball, A. S. (2005): Soil health - a new challenge for microbiologists and chemists. Inter. Microbiol. 8, 13-21.

Buyer, J. S. and Kaufman, D. D. (1996): Microbial diversity in the rhizosphere of corn grown under conventional and low-input systems. Appl. Soil Ecol. 5, 21-27.

Carpenter, S., Walker, B., Anderies, J. M. and Abel, N. (2001): From metaphor to measurement: Resilience of what to what? Ecosystems 4, 765-781.

Demoling, F., Figueroa, D. and Beeth, E. (2007): Comparison of factors limiting growth in different soils. Soil Biol. Biochem. 39, 2485-2495.

Doran, J. W. and Zeiss, M. R. (2000): Soil health and sustainability: managing the biotic component of soil quality. Appl. Soil Ecology 15, 3-11.

Doran, J. W., Sarrantonio, M. and Liebig, M. A. (1996): Soil health and sustainability. Advances in Agronomy $56,1-54$.

Drury, C. F., Stone, J. A. and Findlay, W. I. (1991): Microbial biomass and soil structure associated with corn, grass and legumes. Soil Sci. Soc. Am. J. 55, 805-811.

Emer, N. R., Semenov, A. M., Zelenev, V. V., Zinâkova, N. B., Kostina, N. V. and Golichenkov, M. V. (2014): Daily dynamics of number and activity of nitrogen-fixing bacteria for of virgin and intensely cultivated soils. Eurasian Soil Science. 8, 963-970.

Epelde, L., Becerril, J. M., Alkorta, I. and Garbisum, C. (2014): Adaptive long-term monitoring of soil health in metal phytostabilization: ecological attributes and ecosystem services based on soil microbial parameters. Inter. J. of Phytoremediation 16, 971-981.

Fauci, M. F. and Dick, R. P. (1994): Soil microbial dynamics short and long term effects of inorganic and organic nitrogen. Soil Sci. Soc. Am. J. 58, 801-806.

Finckh, M. R., Van Bruggen, A. H. C. and Tamm, L. (eds) (2015): Plant Diseases and Their Management in Organic Agriculture. APS PRESS. St. Paul, USA. 424 p. 
Garbeva, P., Van Veen, J. A. and Van Elsas, J. D. (2004): Microbial diversity in soil: selection of microbial populations by plant and soil type and implications for disease suppressiveness. Ann Rev Phytopath. 42, $243-270$.

Griffith, B. S., Bonkowski, M., Roy, J. and Ritz, K. (2001): Functional stability, substrate utilization and biological indicators of soils following environmental impacts. Appl. Soil Ecol. 16, 49-61.

Janvier, C., Villeneuve, F., Alabouvette, C., Edel-Hermann, V., Mateille, T. and Steinberg, C. (2007): Soil health through soil disease suppression: Which strategy from descriptors to indicators? Soil Biol. Biochem. 39, 1-23.

Karlen, D. L., Mausbach, M. J., Doran, J. W., Cline, R. G., Harris, R. F. and Schuman, G. E. (1997): Soil quality: A concept, definition, and framework for evaluation. Soil Sci. Soc. Am. J. 61, 4-10.

Karlen, D. L., Andrews, S. S., Wienhold, B. J. and Zobeck, T. M. (2008): Soil Quality Assessment: Past, Present and Future. J. Integr. Biosci. 6, 3-14.

Kirjushin, V. I. (2011): Concept of soil fertility and quality of the soil in the light of a biosphere paradigm of nature management. Materials of All Russian scientific conference "Biosphere-soil-humanity: stability and development". 14-16.3.2011 M: Fund "Infosphere"-the NIA-nature. 202-209. (In Russian).

Kuan, H. L., Hallett, P. D., Griffiths, B. S., Gregory, A. S., Watts, C. W. and Whitmore, A. P. (2007): The biological and physical stability and resilience of a selection of Scottish soils to stresses. Europ. J. Soil Sci. $58,811-821$.

Liebig, M. A., Doran, J. W. and Gardner, J. C. (1996): Evaluation of a field test kit for measuring selected soil quality indicators. Agronomy J. 88, 683-686.

Mader, P., Fließbach, A., Dubois, D., Gunst, L., Fried, P. and Niggli, U. (2002): Soil fertility and biodiversity in organic farming. Science 296, 1694-1697.

Orwin, K. H. and Wardle, D. A. (2004): New indices for quantifying the resistance and resilience of soil biota to exogenous disturbances. Soil Biol. and Biochem. 36, 1907-1912.

Polyanskaya, L. and Zvyagintsev, D. G. (2005): The content and structure of microbial biomass as an indicator of the ecological condition of soils. Soil Science 6, 706-714. (In Russian).

Semenov, A. M. (1991): Physiological bases of oligotrophy of microorganisms and concept of microbial community. Microb. Ecol. 22, 239-247.

Semenov, A. M. (2001): Oscillation of microbial communities in soils. Proc. All Russian Sci. Conference. Devoted to the 100-th anniversary of acad. E. N. Mišhustin. 22.02.2001 M. MAX Press pp. 57-72 (In Russian).

Semenov, A. M. (2005): Trophic groupings and the dynamics of microbial communities in the soil and rhizosphere. The theses of doctor's degree (habilitations), as a scientific report. M. MAX Press 65. p. (In Russian).

Semenov, A. M. (2011): Fundamental laws of ecology to develop ways the definition of soil health. Proc. all Russ. Sci. Conference: "Biosphere-soil-humanity: sustainability and development". Devoted to the 80ann. Prof. A. N. Tiuriukanov. 14-16 march 2011. M. The foundation of "Infosphere"-NIA-Nature. pp. 371-381. (In Russian).

Semenov, A. M. (2015): The health of soil: characteristics of the content and methods of quantifying. Proc. of VIII. Moscow Inter. Congress “Biotechnology: the State and prospects of development”. M. Part 2: 205. (In Russian).

Semenov, A. M. and Van Bruggen, A. H. C. (2011): To a method of soil health parameter determination. Agro XXI. 1-3, 8-10. (In Russian).

Semenov, A. M. and Bubnov, I. A. (2013): Determination of the soil health parameter after different disturbances. Problems of Agricultural Chemistry and Ecology 3, 23-30. (In Russian).

Semenov, A. M. and Sokolov, M. S. (2016): The concept of soil health: fundamental and applied aspects of the substantiation of evaluation criteria. Agrochemistry. 1, 3-16. (In Russian).

Semenov, A. M., Van Bruggen, A. H. C. and Zelenev, V. V. (1999): Moving waves of bacterial populations and total organic carbon along roots of wheat. Microb. Ecol. 37, 116-128.

Semenov, A. M., Kuprianov, A. A. and Van Bruggen, A. H. C. (2010): Transfer of enteric pathogens to successive habitats as part of microbial cycles. Microb. Ecol. 60, 239-249. 
Semenov, A. M., Semenov, V. M. and Van Bruggen, A. H. C. (2011): Diagnostics of soil health and soil quality. Agrochim, 12, 4-20. (In Russian).

Semenov, A. M., Van Bruggen, A. H. C., Bubnov, I. A. and Semenova, E. V. (2011a): The method of soil health parameter determining for soil, composts and other hard substrates. The Russian patent № 2408885. 10.01.2011. (http://bankpatentov.ru/node/62779). (In Russian).

Semenov, A. M., Bubnov, I. A., Semenov, V. M., Semenova, E. V., Zelenev, V. V. and Semenova, N. A. (2013): Daily dynamics of bacterial numbers, $\mathrm{CO} 2$ emissions from soil and relationships between their wave-like fluctuations and succession of the microbial community. Eurasian Soil Science. 46, 869-884.

Sokolov, M. S., Dorodnykh, Yu. L. and Marchenko, A. I. (2010): Healthy soil as a necessary condition of human life. Eurasian Soil Science. 43, 802-809.

Turchin, P. V. (2002): Do general laws in population ecology? J. General Biol. 63, 3-14. (In Russian).

Van Bruggen, A. H. C. and Semenov, A. M. (1999): A new approach to the search of indicators of root disease suppression. Austral-Asian Plant Pathol. 28, 4-10.

Van Bruggen, A. H. C. and Semenov, A. M. (2000): In search of biological indicators for soil health and disease suppression. Appl. Soil Ecol. 15, 13-24.

Van Bruggen, A. H. C. and Semenov A. M. (2015): Soil health and soil borne diseases in organic agriculture. In: M. R. Finckh, A. H. C. Van Bruggen and L. Tamm. (eds): Plant Diseases and Their Management in Organic Agriculture. APS PRESS. St. Paul, USA, pp. 67-90.

Van Bruggen, A. H. C., Semenov, A. M., Van Diepeningen, A. D., de Vos, O. J. and Blok W. J. (2006): Relation between soil health, wave-like fluctuations in microbial populations, and soil-borne plant disease management. Europ. J. Plant Pathol. 115, 105-122.

Zelenev, V. V., Van Bruggen, A. H. C., Leffelaar, P. A., Bloem, J. and Semenov, A. M. (2006): Oscillating dynamics of bacterial populations and their predators in response to fresh organic matter added to soil: The simulation model 'BACWAVE-WEB'. Soil Biol. Biochem. 38, 1690-1711.

Zvyagintsev, D. G. (1987): The soil and the microorganisms. M. Publ. Lomonosov Moscow State University, 256. p. (In Russian). 